\title{
The genetic basis of intradural spinal tumors and its impact on clinical treatment
}

\author{
Michael Karsy, MD, PhD, Jian Guan, MD, Walavan Sivakumar, MD, Jayson A. Neil, MD, \\ Meic H. Schmidt, MD, MBA, and Mark A. Mahan, MD \\ Department of Neurosurgery, Clinical Neurosciences Center, The University of Utah, Salt Lake City, Utah
}

\begin{abstract}
Genetic alterations in the cells of intradural spinal tumors can have a significant impact on the treatment options, counseling, and prognosis for patients. Although surgery is the primary therapy for most intradural tumors, radiochemotherapeutic modalities and targeted interventions play an ever-evolving role in treating aggressive cancers and in addressing cancer recurrence in long-term survivors. Recent studies have helped delineate specific genetic and molecular differences between intradural spinal tumors and their intracranial counterparts and have also identified significant variation in therapeutic effects on these tumors. This review discusses the genetic and molecular alterations in the most common intradural spinal tumors in both adult and pediatric patients, including nerve sheath tumors (that is, neurofibroma and schwannoma), meningioma, ependymoma, astrocytoma (that is, low-grade glioma, anaplastic astrocytoma, and glioblastoma), hemangioblastoma, and medulloblastoma. It also examines the genetics of metastatic tumors to the spinal cord, arising either from the CNS or from systemic sources. Importantly, the impact of this knowledge on therapeutic options and its application to clinical practice are discussed.
\end{abstract}

http://thejns.org/doi/abs/10.3171/2015.5.FOCUS15143

KEY WORDS spinal tumor; astrocytoma; ependymoma; hemangioblastoma; neurofibroma; genetics; molecular biology

I NTRADURAL spinal tumors have an incidence of 0.64 per 100,000 person-years and account for $3 \%$ of primary CNS tumors. ${ }^{78}$ Although intradural spinal tumors represent a limited overall tumor burden in the population, these tumors frequently cause significant morbidity associated with long-term survival. This review will focus on the known genetic and molecular underpinnings of intradural spinal tumors and on the potential clinical impact of this knowledge (Table 1).

Genetic alterations provide information about a tumor's pathophysiological origin and may also serve as markers for evaluating clinical outcomes. Accordingly, knowledge about the mutations in an individual's tumor can more precisely define a patient's prognosis and risk for cancer recurrence, which may meaningfully inform counseling. ${ }^{51}$ Variation in genetic alterations may also inform tumor classification and identify cells of origin for different tumor types, as has been shown for medulloblastoma. ${ }^{30}$ Outcome studies based on genetics may prompt reconsideration of standard therapies for broad tumor categories, as clinical evidence may suggest tailored chemoradiation therapies. Enticingly, a deeper genetic understanding provides the opportunity to investigate targeted therapies, particularly to combat aggressive tumors and recurrence in long-term survivors. The most recent development of a targeted inhibitor has been the PD-1 inhibitor nivolumab to treat patients with melanoma. ${ }^{88}$ Although improved knowledge about the molecular workings of tumors is unlikely to challenge the primacy of surgical treatment in the immediate future, a better understanding of tumor genetics may lead to better treatment for intradural spinal tumors.

Intradural tumors are classified as extramedullary or intramedullary, depending on their relationship with the spinal cord. Each of these 2 types is associated with a cer-

ABBREVIATIONS ALK = anaplastic lymphoma kinase; BRAF = B-Raf proto-oncogene, serine/threonine kinase; EGFR = epidermal growth factor receptor; GBM = glioblastoma; HIF1 $\alpha$ = hypoxia-inducible factor $1 \alpha$; ISCM = intramedullary spinal cord metastasis; MAPK = mitogen-activated protein kinase; MMP-9 = matrix metalloproteinase 9; $\mathrm{mTOR}=$ mechanistic target of rapamycin; NF = neurofibromin; NST = nerve sheath tumor; $\mathrm{p53}=$ the protein p53; PDGF = platelet-derived growth factor; PI3K = phosphoinositide 3-kinase; PKB = protein kinase B; PTEN = phosphatase and tensin homolog; SHH = sonic hedgehog; SMARCE1 = SWI/SNF-related matrix-associated actindependent regulator of chromatin E1; VEGF = vascular endothelial growth factor; VHL = von Hippel-Lindau.

SUBMITTED March 20, 2015. ACCEPTED May 20, 2015

INCLUDE WHEN CITING DOI: 10.3171/2015.5.FOCUS15143.

DISCLOSURE The authors report no conflict of interest concerning the materials or methods used in this study or the findings specified in this paper. 


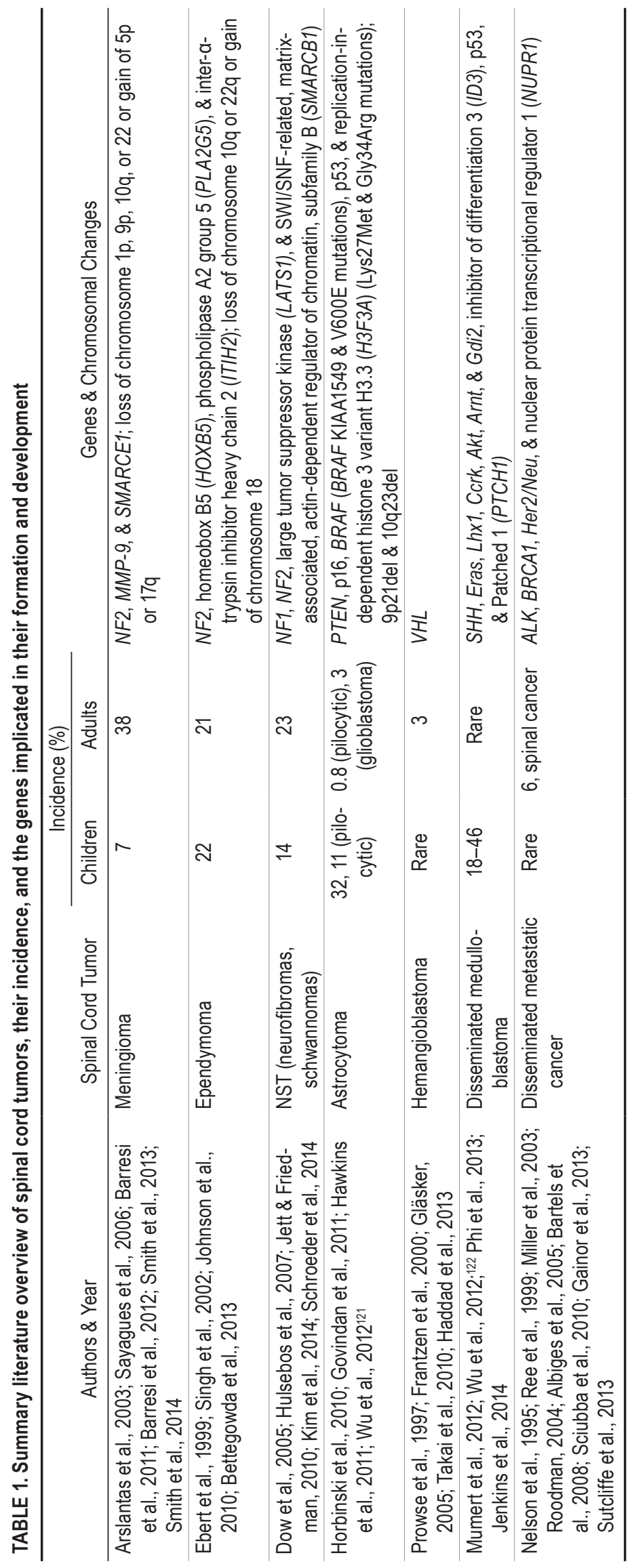


tain pathological development and requires distinct clinical treatment approaches (Fig. 1). Intramedullary tumors account for $5 \%-10 \%$ of all spinal tumors but are more common in children. ${ }^{112}$ Among patients 19 years of age or younger, ependymomas (22\%), nerve sheath tumors (NSTs; $14 \%$ ), pilocytic astrocytomas (11\%), and meningiomas $(6 \%)$ are the most common intradural tumors, ${ }^{78}$ whereas in patients older than 20 years of age, meningiomas (38\%), NSTs (23\%), and ependymomas (21\%) are the most common (Fig. 2). Less frequent diagnoses of intradural tumors in adults include lymphomas (2\%), glioblastomas (GBMs; 3\%), hemangiomas (3\%), and pilocytic astrocytomas $(0.8 \%)$. Systemic metastatic disease may also spread within the spinal dura or cord but is most commonly limited to the extradural space. Although many other intradural lesions, such as vascular malformations (for example, cavernous angiomas and arteriovenous malformations), cysts, lipomas, dermoids/epidermoids, and paragangliomas, should be considered, the genetics of these specific pathologies are not included in this review.

\section{Nerve Sheath Tumors}

Although both neurofibromas and schwannomas arise from Schwann cells, each of these tumor types displays distinct clinicopathological characteristics during the formation of intradural, extramedullary spinal tumors. Spinal NSTs account for $23 \%$ of intradural spinal tumors in adults and for $14 \%$ in pediatric patients. ${ }^{18}$ Most spinal NSTs $(75 \%-80 \%)$ reside intradurally, but about $10 \%-15 \%$ of these tumors extend through the dural root sleeve as a dumbbell-shaped tumor with intradural and extradural components; $10 \%$ of spinal NSTs are located extramedullary and $1 \%$ are located intramedullary. ${ }^{67}$ Furthermore, $0.7 \%$ of spinal NSTs are malignant, resulting in an exceedingly poor prognosis (that is, a median overall survival of 22 months), irrespective of cranial or spinal location. ${ }^{87}$
Malignant NSTs may arise without known preexisting lesions in both cranial and spinal cases, suggesting that tumor malignancy may develop without obvious transformation of a low-grade tumor.

Nerve sheath tumors, as well as other intradural spinal cancers, are more common in patients with neurofibromatosis Type 1, a condition that results from a mutation in the neurofibromin 1 (NF1) gene located on chromosome $17 \mathrm{q} 11 .{ }^{48} \mathrm{NF1}$ encodes a protease involved in Ras-GTP phosphorylation, which reduces activation of downstream mitogen-activated protein kinases (MAPKs) involved in cell proliferation and survival. Mutations in NF1 show an incidence of 1 in 3000 people and are associated with neurofibroma formation in the spine and in peripheral nerves. In addition, NF1 mutations are associated with an elevated risk for the development of malignant peripheral NSTs and of a set of diverse tumors, including optic nerve gliomas, rhabdomyosarcomas, pheochromocytomas, and carcinoid tumors. Although familial NFl is transmitted in an autosomal dominant manner, sporadic mutations of $N F 1$ are observed in $50 \%$ of cases of spinal neurofibromas, with missense and nonsense mutations being the most common types.

Mutations in the neurofibromin 2 (NF2) gene, located on chromosome 22q12.2, also play a role in NSTs of the spine. Familial neurofibromatosis Type 2 most commonly arises as a germline mutation in $N F 2$, also known as merlin, and has a prevalence of 1 in 33,000. ${ }^{23}$ The NF2 protein is member of the ERM (ezrin, radixin, and moesin) family of proteins, linking cytoskeletal components with proteins of the cell membrane that regulate cytoskeletal dynamics and cell-to-cell communication. Mutations in NF2 may lead to the development of vestibular schwannomas (classically bilateral tumors of cranial nerve XIII), neurofibromas, ependymomas, gliomas, and meningiomas. ${ }^{19,97} \mathrm{Ap}-$ proximately two-thirds of patients with neurofibromatosis Type 2 develop spinal tumors, which include spinal epen-

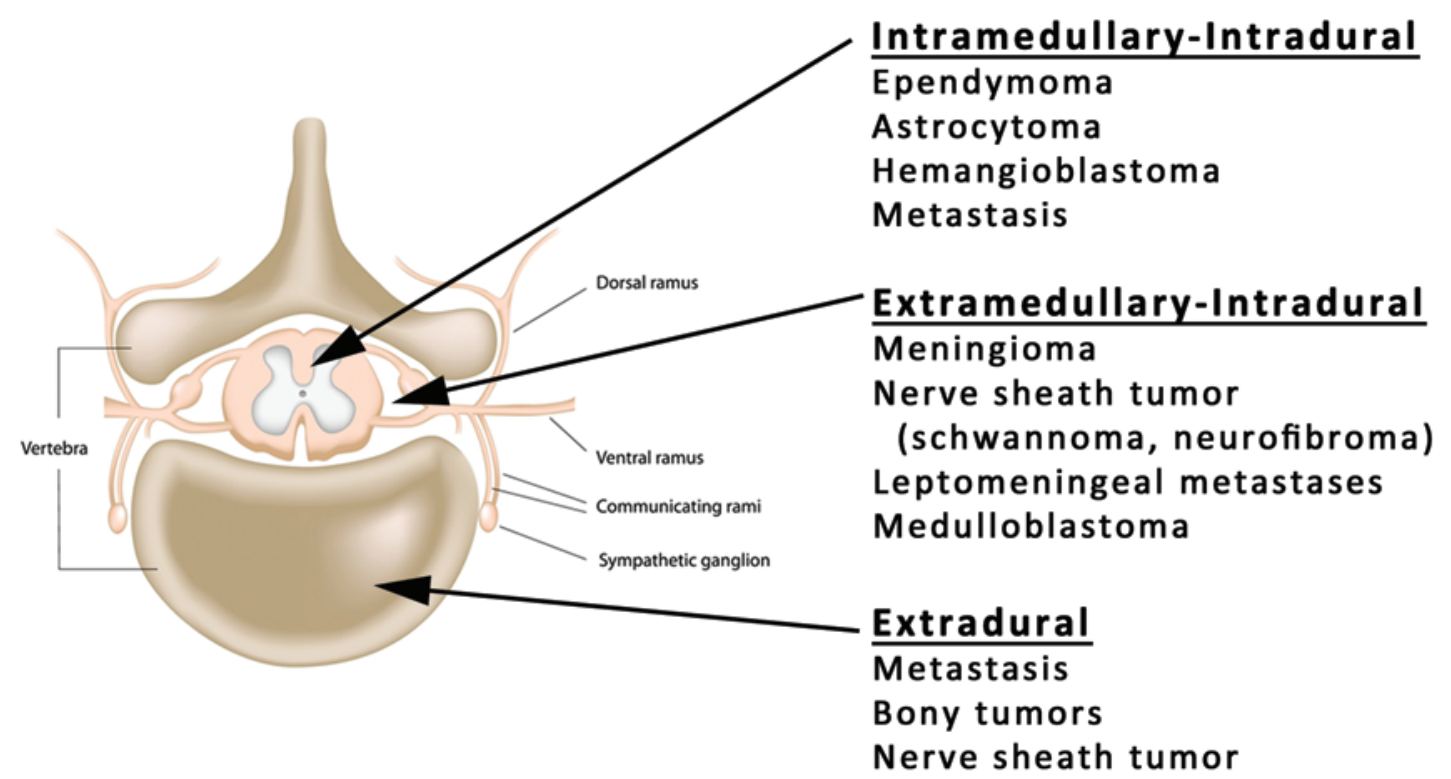

FIG. 1. Illustration showing the distribution of the most common primary spinal cord tumors by type and location. Copyright Fotosearch (www.fotosearch.com). Published with permission. 


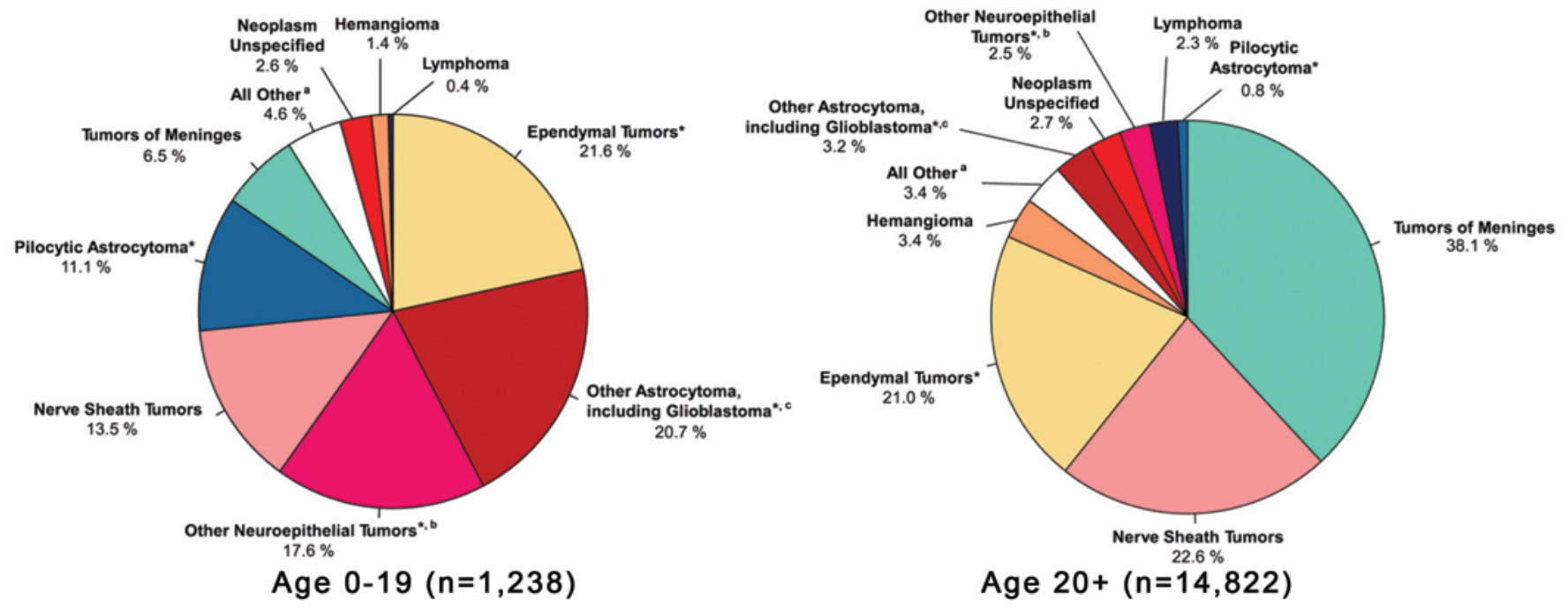

FIG. 2. Pie charts showing the distribution of primary spinal cord lesions in (left) pediatric (age 0-19 years) and (right) adult (age 20 years or older) patients; the charts were produced with data from the Central Brain Tumor Registry of the United States (CBTRUS) Statistical Report. Data were aggregated from the National Program of Cancer Registries and Surveillance, Epidemiology, and End Results databases from 2007 to 2011, including only primary cancers. *All or some of this histological type are included in the CBTRUS definition of gliomas, including ICD-0-3 histological codes 9380-9384, 9391-9460, and 9480. Percentages may not add up to $100 \%$ because of rounding. alncludes embryonal tumors, other tumors of cranial and spinal nerves, other hematopoietic neoplasms, germ cell tumors, neoplasms unspecified, and all other. 'Includes oligodendroglioma, anaplastic oligodendroglioma, oligoastrocytic tumors, glioma malignant, choroid plexus tumors, not otherwise specified, other neuroepithelial tumors, and neuronal and mixed neuronal-glial tumors. 'Includes diffuse astrocytoma, anaplastic astrocytoma, and unique astrocytoma variants. From Ostrom et al., Neuro-Oncology 16:iv1-iv63, 2014. Copyright Oxford University Press. Published with permission.

dymomas, meningiomas, and NSTs. Mutations of NF2 in spinal ependymoma and meningioma are reviewed below.

One study reported a mutation in the gene for large tumor suppressor kinase (LATS1), a downstream mediator of NF2, in a case of spinal schwannoma in a patient with Li-Fraumeni syndrome and with a germline mutation in the gene for the protein $\mathrm{p} 53$, but the clinical relevance of these alterations remains unknown. ${ }^{57}$ Mutations in INII/ $S M A R B 1$, a gene involved in chromatin remodeling, have been observed in familial schwannomatosis similar to mutations in SWI/SNF-related matrix-associated actindependent regulator of chromatin E1 (SMARCEI) in cases of multiple familial spinal meningiomas. ${ }^{43}$ These results support the importance of these genetic alterations in NSTs of the intradural spinal space but leave open questions about the interaction of NF2 with associated genetic changes and the potential for targeted therapy.

Treatments for both benign and malignant peripheral NSTs have been initiated, which may open windows into the treatment of spinal NSTs. Recent trials have sought to design treatments that target tumors arising from $N F 1$ or NF2 mutations. ${ }^{125}$ Treatment with tipifarnib, a farnesyl transferase inhibitor that reduces upregulated Ras signaling resulting from some $N F 1$ mutations, was evaluated in a Phase I trial involving children with solid tumors and plexiform neurofibromas, who showed stable disease during the follow-up period of this trial. ${ }^{118}$ In other trials, however, tipifarnib did not prolong time to imaging-confirmed enlargement of plexiform neurofibromas. ${ }^{17}$ Other potential targets have been studied in patients with NFI mutations and with progressive peripheral neurofibroma during trials of sirolimus (an inhibitor of mechanistic target of rapamycin $[\mathrm{mTOR}]),{ }^{116} \mathrm{PD} 0325901$ (an inhibitor of MEK, a MAPK kinase), ${ }^{47}$ pegylated interferon- $\alpha-2 b,{ }^{45}$ imatinib (a c-kit and platelet-derived growth factor receptor- $\beta$ [PDGFR $\beta$ ] inhibitor), ${ }^{89}$ and sorafenib (inhibitor of c-kit, PDGFR $\beta$, RAF, and vascular endothelial growth factor [VEGF] receptor 2]): ${ }^{55}$ however, the results of these trials have indicated only limited clinical improvement or were obtained in trials with sample sizes too low to support clinical use of these agents. Such targeted treatment approaches have not yet been attempted in intradural spinal NSTs.

\section{Meningiomas}

Meningiomas are extramedullary, intradural tumors arising from meningothelial arachnoid cap cells within the spinal dura. Spinal meningiomas are the most common spinal tumors in adults, accounting for up to $38 \%$ of intradural spinal tumors but only for $6.5 \%$ of overall craniospinal tumors in this age group. ${ }^{78}$ Similar histological subtypes are observed in both intracranial and spinal meningiomas, including meningothelial, metaplastic, psammomatous, transitional, atypical, and clear cell types. The psammomatous, meningothelial, and transitional subtypes are the most common meningiomas of the spine and, for reasons that are unknown, show a lower risk for recurrence than their intracranial counterparts. ${ }^{94,96,101}$ Compared with resection of other meningioma subtypes, resection of psammomatous spinal meningiomas is associated with poorer neurological outcomes postoperatively $.^{96} \mathrm{Al}-$ though malignant transformation of spinal meningiomas, like that of their intracranial counterparts, does occur, this transformation accounts for just $3 \%$ of cases. ${ }^{101}$

Multiple genes have been associated with spinal menin- 
giomas. Several studies have reported deletion of chromosome $22 \mathrm{q}$ and of its associated gene $N F 2$ in cases of spinal meningioma. ${ }^{4,95}$ A comparative DNA microarray study of 7 spinal and 11 intracranial meningiomas found that spinal meningiomas were more commonly associated with the psammomatous and transitional subtypes along with a greater likelihood of chromosome 22 deletion. ${ }^{95}$ In that study, interphase-fluorescence in situ hybridization was used to generate tumor karyotypes, which visualize the cell's entire chromosome set; the results showed that spinal meningiomas were more likely to arise from a singlecell clone rather than from a collection of cells. The study also reported differential expression of 1555 genes in spinal and intracranial meningiomas. Thirty-five of these genes were more highly expressed in spinal meningiomas than in intracranial tumors, including those involved in transcription (that is, Hox genes, the NR4 family of genes, KLF4, FOSL2, and TCF8) and in intracellular (RGS16, DUSP5, DUSP1, SOCS3, and CMKOR) and extracellular (L6, TGFB1I4, ILIB, CYR61, and CDH2) signaling.

Another study of 16 patients with spinal meningioma showed that the cells of these tumors most commonly displayed complete or partial loss of chromosome 22, along with loss of $1 \mathrm{p}, 9 \mathrm{p}$, and $10 \mathrm{q}$ and with gain of $5 \mathrm{p}$ and $17 \mathrm{q}$, compared with the chromosome complement in the patients' own lymphocytes. ${ }^{4}$ These chromosomal changes were most common in the atypical and anaplastic subtypes. Current clinical treatment algorithms do not distinguish between spinal and cranial meningiomas despite their underlying differences. Furthermore, the above findings suggest distinct genetic mechanisms for these 2 diseases, which may influence the clinical prognosis of the patients affected.

In addition to chromosomal alterations, changes to individual genes have also been observed in spinal meningioma. One study reported that spinal meningiomas had upregulated expression of the matrix metalloproteinase family of proteins involved in cell growth and invasion. ${ }^{5}$ The authors measured gene expression in 58 spinal meningiomas, and upregulated expression of matrix metalloproteinase 9 (MMP-9) was observed in $46 \%$ of them. Only 1 case of recurrent meningioma was included, and no overall correlation with survival was detected. In contrast to MMP-9 expression in spinal meningiomas, MMP9 expression in intracranial meningiomas correlates with a more aggressive histological grade and proliferation index of the tumor and with a poorer prognosis. ${ }^{6}$

Mutations in SMARCE1, which is involved in the regulation of secondary DNA structure within chromosomes, have also been reported to be important in the formation of multiple spinal meningiomas. ${ }^{105}$ The study by Smith and colleagues identified SMARCE1 mutations in a group of individuals with familial multiple spinal meningiomas without NF2 mutations. Furthermore, SMARCE1 is mutated in cranial meningioma and associated with the clear cell subtype, which is a WHO Grade II tumor that tends to metastasize more frequently than other subtypes. ${ }^{106}$ Importantly, many of the extensively studied gene mutations in intracranial meningioma (for example, in the genes differentially expressed in adenocarcinoma of the lung [DALI], tissue inhibitor of metalloproteinases 1 [TIMP1], p16, p15, pl4ARF, N-Myc downstream-regulated gene 2 [NDRG2], adaptor-related protein complex $1, \beta 1$ subunit [ADTB1], deleted in liver cancer 1 [DLCl], $c$-myc, bcl-2, and signal transducer and activator of transcription 3 [STAT3]) and their respective molecular pathways have yet to be fully evaluated in spinal meningiomas. ${ }^{79}$ Accordingly, the prognostic impact and the potential for targeted therapy of these genetic alterations still await full elucidation in spinal meningiomas. Current treatments of more aggressive spinal meningiomas are limited, and better identification of critical gene targets may improve therapeutic targeting.

Although the genetic alterations in spinal meningiomas may differ from those in intracranial meningiomas, recent studies have investigated the use of gene targeting and molecular therapies to address both diseases. Oncolytic therapy has used herpes simplex virus 1 (HSV-1), adenoviruses, vaccinia virus, and retroviruses for transfecting genes into tumor cells to induce apoptosis in meningiomas. ${ }^{16}$ Experimental transfection with $N F 2$ in an animal meningioma model ${ }^{44}$ and with the Ras pathway inhibitor Ha-RasN17 in an in vitro meningioma model ${ }^{103}$ has been successful. In addition, transfection of small interfering RNA (siRNA) constructs to reduce or silence expression of cathepsin $B$ and $M M P-9$ genes reduces meningioma migration and invasion in vivo. ${ }^{113}$ Similarly, siRNA targeting of $u P A R /$ cathepsin $B$ and $u P A / u P A R$ genes, involved in the urokinase-type plasminogen activator (uPA) system, reduces markers of tumor angiogenesis in meningioma. ${ }^{36}$ Some genes involved in intracranial meningioma, including NF2 and MMP-9, may be also suitable targets in spinal meningioma but have not yet been targeted in clinical trials.

Several recent trials have evaluated the potential of the anti-VEGF drug bevacizumab in treating intracranial meningioma. ${ }^{38,64,73,76,83}$ One trial with 48 patients having intracranial meningioma who were followed up for a median period of 18 months showed that $29 \%$ of these patients had at least a $20 \%$ reduction in meningioma volume, ${ }^{76}$ however, this reduction was not sustained over time, and a molecular analysis yielded no correlation of VEGF pathway expression with treatment responses. Identifying the critical gene targets in spinal meningioma will improve the design of clinical treatments. Such efforts may be aided by advances in tissue engineering, which may make it possible to test therapeutics in vitro before any in vivo administration. ${ }^{26}$

\section{Ependymomas}

Ependymomas are the most common spinal cord tumors in pediatric patients $(22 \%)$ and are also common in adults $(21 \%) .{ }^{78}$ Most ependymomas in pediatric patients occur intracranially; within the spine, they occur most commonly in the filum terminale or conus. ${ }^{114}$ In adults, ependymomas most often occur in the cervical spine and filum terminale. Ependymomas are classified as subependymoma or myxopapillary (WHO Grade I), ependymoma (WHO Grade II), or anaplastic (WHO Grade III). In both children and adults, the myxopapillary variant is most prevalent. Although they were previously presumed to originate from ependymal cells in the central canal, both spinal and intracranial ependymomas are now thought to arise from radial glial stem/progenitor cells. ${ }^{49,110}$ Interest- 
ingly, the cell of origin may be associated with the clinically observed pattern of this tumor, as spinal ependymomas may be located intramedullary or extramedullary or may represent a combination of both.

Multiple genetic patterns differentiate spinal ependymomas from intracranial ependymomas. In a transcriptomic study of 39 ependymoma tumors, including 10 spinal ependymomas, unbiased hierarchical clustering, which categorizes tumors according to quantitative mRNA expression levels alone, separated samples into supratentorial, posterior fossa, and posterior fossa spine categories. ${ }^{60}$ Spinal ependymomas showed high levels of homeobox B5 (HOXB5), phospholipase A2 group 5 (PLA2G5), and inter- $\alpha$-trypsin inhibitor heavy chain 2 (ITIH2) expression and low levels of $N F 2$ expression. In additional studies, an NF2 mutation was observed in 30\%-40\% of spinal ependymomas and was observed only in spinal ependymomas in studies that also included intracranial ependymomas. ${ }^{104}$ Similarly, another study of 8 spinal and 8 intracranial ependymomas reported significant losses of chromosome 22 , on which NF2 resides, in spinal ependymoma. ${ }^{8}$ In addition, an unexpected partial loss of chromosome 13 was observed. In addition, loss of chromosome 10q has been reported in a study of a small number of spinal ependymomas. ${ }^{20}$ The overall mutation rates in spinal ependymomas were quite low in this study, averaging 12.9 mutations per spinal ependymoma and 12.8 mutations per intracranial ependymoma (by comparison, rates of up to 450 mutations per tumor have been observed in lung cancer). ${ }^{10}$ These lower mutation rates may improve identification of gene targets in spinal ependymomas to expand therapeutic approaches.

A comparative genomic hybridization analysis with custom DNA probes for tumor karyotyping showed chromosomal morphologies that were distinct for intracranial and spinal ependymomas and chromosomal differences among the different histological subtypes (that is, myxopapillary, classic, and anaplastic). ${ }^{11}$ Balanced chromosomal translocations were observed in $32 \%$ of intracranial ependymomas but in only $3 \%$ of spinal ependymomas. Gains across entire chromosomes were common in spinal $(64 \%)$ and adult cranial (56\%) ependymomas. Loss of chromosome $22 \mathrm{q}$ was observed in $50 \%$ of medullary ependymomas, and other chromosomal changes were common in other types (for example, gain of chromosome 1q in pediatric posterior fossa tumors and anaplastic tumors, mutations on chromosome 10 in myxopapillary subtypes, and loss of $6 \mathrm{q}$ in adult posterior fossa tumors).

Johnson and colleagues ${ }^{49}$ recently used a novel approach for delineating relative genetic differences between spinal and intracranial ependymomas. This study compared the genetic profiles in human ependymomas compared with those in mouse tumor models. Gene expression patterns in human cranial ependymomas resembled the patterns in mouse neural stem cells in a p16-mutated background (Ink4a/Arf $\left.{ }^{\prime-}\right)$. On the other hand, expression patterns in human spinal ependymomas were similar to those in normal mouse neural stem cells. Although limited to a comparison of human and murine gene expression, the observations in this study suggested that spinal ependymomas reflect an adult genotype, whereas intracranial ependymomas reflect a pediatric genetic program. Spinal ependymomas showed significant losses of chromosome 22q similar to losses observed in intracranial ependymoma, but spinal ependymomas also showed unique gains of chromosome 18, which were not observed in intracranial tumors. These results also support the idea that distinct molecular approaches to treating these tumors would warrant further investigation.

Although studies have identified various molecular targets in ependymomas, few clinical trials have explored the efficacy of treatments involving these targets. ${ }^{119}$ Investigation of the PI3K signaling pathway in pediatric ependymomas indicated that upregulation of protein kinase $\mathrm{B}$ (PKB or Akt protein kinase) and PI3K correlates with poorer progression-free survival. ${ }^{91}$ Although both PKB and PI3K are potential therapeutic targets, their expression was lower in spinal ependymomas, which could potentially limit their usefulness in treatments of these tumors. Upregulated expression of epidermal growth factor receptor (EGFR) in intracranial ependymomas correlates with poor prognosis; this association was further demonstrated by targeted inhibition of EGFR with gefitinib and with AEE788, which reduced tumor proliferation in an in vivo model. ${ }^{68,100}$ These results suggest that inhibition of EGFR may prove beneficial in spinal ependymomas, should it be validated as a tumor driver. Subgroup C supratentorial ependymomas have been successfully targeted with the histone deacetylase inhibitors vorinostat and panobinostat. ${ }^{69}$ Targeting of the Notch-signaling pathway with a $\gamma$-secretase inhibitor (MK-0752) was well tolerated and achieved stable disease during a Phase I trial in 1 patient with intracranial ependymoma. ${ }^{27}$

Targeted therapy for spinal ependymomas is also scarcely described in the literature, although a report of a PDGF-expressing tumor that responded to treatment with imatinib suggests that this medication may have a potential for treating such tumors. ${ }^{24}$ Treatment options involving viral delivery for ependymomas have been limited, but 1 Phase I trial has demonstrated successful retroviral transfection with the herpes simplex virus in an adolescent patient with intracranial ependymoma. ${ }^{62}$ The results of this trial indicated elevated levels of interleukin 12 and Fas ligand and of peripheral T cells and B cells, as well as enhanced T-cell activation, consistent with upregulation of the immune system. Another trial investigated expression of EphA2, interleukin-13R $\alpha 2$, survivin, and Wilms tumor protein (WT1) in pediatric ependymomas as a preliminary basis for use of an existing multiprotein, peptide-based glioma vaccine. ${ }^{126}$ The results of the trial suggested variable expression of these tumor-associated antigens in cranial ependymoma and therefore have potential implications for future clinical trials. Further studies of molecular targets in ependymoma tumors and specifically of application in treatments for spinal ependymomas are warranted.

\section{Astrocytomas}

Intramedullary spinal astrocytomas arise from astrocytes within the spinal cord. They account for $32 \%$ of all spinal cord tumors in children and for $4 \%$ of all spinal cord tumors in adults ${ }^{78}$ and comprise approximately $90 \%$ of all intramedullary spinal cord tumors in pediatric patients. ${ }^{78}$ Similar to the astrocytic tumors in the brain, astrocytomas 
in the spine include pilocytic astrocytoma (WHO Grade I); diffuse, low-grade, or fibrillary astrocytoma (WHO Grade II); anaplastic astrocytoma (WHO Grade III); and GBM (WHO Grade IV). ${ }^{72}$ Pilocytic astrocytomas account for $11 \%$ of tumors in the spines of children but are rare in the spines of adults $(0.8 \%)$. Fibrillary astrocytomas are the most common subtype in adults $(89 \%)$, and malignant astrocytoma accounts for $10 \%$ of intramedullary astrocytomas. Astrocytomas with WHO Grade II and above occur in $20.7 \%$ of pediatric and adolescent spinal cord tumors compared with $3.2 \%$ of adult spinal cord tumors. Most astrocytomas $(60 \%)$ occur in the cervicothoracic segments, although these lesions are observed throughout the spine.

Although many studies have investigated the genetics of intracranial astrocytomas, fewer studies have probed the genetics of astrocytomas occurring in the spinal cord. Some common mutations observed in cranial GBMs are also noted in spinal astrocytomas, including mutations in the 16 gene, the phosphatase and tensin homolog (PTEN) gene, the B-Raf proto-oncogene $(B R A F), p 53$, and the replication-independent histone 3 variant $\mathrm{H} 3.3$ gene (H3F3A). In 1 study of 9 cases of pilocytic astrocytoma, mutations were found in p16 and on 9p21, the chromosome where it is located, as well as on the PTEN-containing chromosome $10 \mathrm{q} 23 .{ }^{40}$ The pl6 gene encodes a cell-cycle regulatory protein, and its mutation may result in unregulated cell proliferation. PTEN is involved in regulating phosphorylation of membrane-bound phosphatidylinositol, which influences downstream PKB/Akt signaling to induce cell proliferation, migration, and mRNA translation. Importantly, numerous downstream targets from PTEN have been identified, such as mTOR and Akt, and several chemical antagonists of these effector proteins are currently under clinical investigation for managing cranial astrocytoma, which may offer the possibility of expanding treatments to spinal astrocytoma..$^{33}$

In 2 studies of spinal astrocytoma, the $B R A F$ gene has also been observed to contain mutations, namely the $B R A F-K I A A 1549$ fusion gene and $B R A F^{V 600 E}$ mutation. ${ }^{39,40}$ $\mathrm{BRAF}$ is a membrane-bound proto-oncogene involved in regulating cell proliferation and survival. Mutations in the $B R A F$ gene result in a constitutively active protein that promotes tumor formation. Constitutive activation of $B R A F$ has not been shown to consistently result in a poorer prognosis for patients with cranial and spinal astrocytomas. ${ }^{39,42}$ The BRAF protein has been successfully targeted in some cancers, such as in melanoma treatment with vemurafenib, and has been tested as a potential target in cranial GBM. ${ }^{42}$

High expression of p53, which may be observed after a mutation in its gene, has been observed in a few cases of spinal GBMs. ${ }^{34}$ Although $p 53$ mutations have been commonly reported and have been extensively studied in cranial GBMs, further investigation is required to study p53 mutation levels, mutation subtypes, and interaction with other p53 pathway proteins such as MDM2, an E3 ubiquitin ligase that affects p53 activity, and the Rb protein, a tumor suppressor, in spinal GBMs. ${ }^{22}$ Various targets within the p53 pathway have been identified but have yielded limited efficacy in controlling GBM. In addition, mutations in $H 3 F 3 A$, which is involved in regulating DNA folding and gene expression, have been observed in $36 \%$ of nonbrainstem GBMs. ${ }^{121}$ Two distinct mutations, Lys27Met and Gly34Arg, have been predominantly associated with brainstem or spine and supratentorial GBMs, respectively. ${ }^{121}$ Unlike for many of the other spinal tumor types, multiple mutational targets have been identified for astrocytoma owing to the development of treatments for cranial astrocytoma. Further investigation into the efficacy of these treatments for recurrent or aggressive astrocytoma of the spine may be warranted.

Several studies have investigated gene targeting and clinical efficacy of various agents in the treatment of intracranial astrocytoma, namely GBM, but few studies have explored potential treatment of spinal astrocytomas. ${ }^{51}$ Targeting of the PI3K/PKB/mTOR pathway, ${ }^{35,93} \mathrm{p} 53,{ }^{22}$ and $\mathrm{BRAF}^{90}$ has been attempted in intracranial gliomas with limited success; many of these targeted approaches have not yet been tested in astrocytoma of the spinal cord because of the greater rarity of this condition. One potential target for inhibiting spinal cord astrocytoma formation and progression is hyaluronan, a nonsulfated glycosaminoglycan distributed throughout connective and neural tissue. For example, oligomers to hyaluronan suppressed the in vivo growth of spinal cord astrocytoma. ${ }^{66}$ Another potential approach involves treatment with genetically modified Salmonella typhimurium to suppress in vivo growth of a spinal astrocytoma model; ${ }^{58}$ however, the mechanism for this approach remains unknown.

Many researchers have studied the feasibility of targeting gliomas with viral delivery methods, which have attracted significant clinical interest. ${ }^{17}$ As of 2012, approximately 20 clinical trials with 7 different oncolytic viruses in the treatment of GBM had been completed, ${ }^{120}$ and although the safety of this approach has been evident, its clinical efficacy and application remain under investigation. This potential treatment approach can be applied to spinal astrocytoma, which shares many of the same genetic alterations with its intracranial counterpart.

\section{Hemangioblastomas}

Hemangioblastomas are benign tumors that account for $2 \%-8 \%$ of intramedullary tumors and show a low prevalence in childhood. . $^{33,37,78}$ Approximately $25 \%$ of hemangioblastoma patients have evidence of familial von HippelLindau (VHL) disease characterized by the VHL mutation. The VHL gene encodes an E3 ubiquitin ligase that targets hypoxia-inducible factor $1 \alpha$ (HIF $1 \alpha)$, which regulates cell metabolism and vascular proliferation. The VHL gene resides on chromosome 3p25-26 and is transmitted in an autosomal dominant fashion with $90 \%$ gene penetrance. VHL disease results in symptoms at earlier ages, including associated tumors such as CNS hemangioblastoma, retinal angioma, renal cysts, clear cell renal carcinoma, pancreatic cysts, pheochromocytoma, epididymal cystadenoma, and pancreatic neuroendocrine tumor. A CNS hemangioblastoma can occur without (Type I) and with (Type II) pheochromocytoma.

Approximately $80 \%$ of hemangioblastomas develop in the posterior fossa, and $20 \%$ occur in the cervical or lumbar spine.$^{78}$ Missense mutations are common in familial VHL disease, but sporadic mutations and deletions have 
also been observed in sporadic and VHL-related spinal hemangioblastoma. Hypermethylation of VHL is also a possible mechanism of protein inactivation. ${ }^{82}$ The impact of VHL mutations on spinal hemangioblastoma has not been extensively studied, but 1 study reported that spinal hemangioblastomas were strongly associated with the VHL syndrome (in $88 \%$ of cases) but occurred less frequently in sporadic cases $(21 \%)$ and often were associated with significant VHL expression in multilevel disease. ${ }^{109}$ Overall, the understanding of the role of mutated genes other than VHL in spinal hemangioblastoma remains limited.

Potential molecular targets of hemangioblastoma, namely the VEGF and HIF $1 \alpha$ proteins, may offer avenues to treat patients with this tumor type or with other tumors that rely on neovascularization. The anti-VEGF agent and angiogenesis inhibitor bevacizumab has been approved by the US Food and Drug Administration for various tumors, including metastatic ovarian, cervical, breast, colorectal and renal cell carcinoma, non-small cell lung carcinoma, and recurrent GBM. Results from clinical trials with GBM patients have indicated that anti-VEGF therapies such as bevacizumab improved progression-free survival and performance status but not overall survival. ${ }^{53}$ Targeting HIF1 $\alpha$ reduces growth of GBM in vivo and decreases the expression of both VEGF and glucose transporter 1 (GLUT1), which are implicated in neovascularization and tumor metabolism, respectively. ${ }^{32}$ Treatment with antiVEGF inhibitors has been investigated during the in vivo treatment of $V H L$-null renal cell carcinoma ${ }^{123}$ and of $V H L-$ associated retinal hemangioblastomas. ${ }^{41} \mathrm{~A}$ recent study showed that variable expression of $V E G F-A, V H L$, and $V E G F-C$ along with other genes may predict the efficacy of bevacizumab..$^{15}$ Other molecular markers or factors are probably also important in regulating the therapeutic efficacy of bevacizumab. Both anti-VEGF and anti-HIF1 $\alpha$ treatments have shown limited efficacy in managing intracranial tumors and have not yet been fully investigated for hemangioblastomas.

\section{Disseminated Medulloblastomas}

Medulloblastomas are malignant brain tumors that arise from cerebellar granule precursor cells in the developing cerebellum of children. ${ }^{84,85}$ Transcriptome analysis in large cohorts of medulloblastoma patients has shown that these lesions make up a diverse set of tumors that differ in gene expression profiles, rates of metastasis, and overall patient survival. ${ }^{13,59,111}$ Most notably in children, an increasingly accepted predictor of shortened survival times is the presence of metastasis to the spine. ${ }^{21}$ Metastasis rates appear to vary among the 4 genetic subgroups of medulloblastoma (17.9\% in the Wnt subgroup, $19.1 \%$ in the sonic hedgehog [SHH] subgroup, $46.5 \%$ in Subgroup C, and $29.7 \%$ in Subgroup D). ${ }^{75}$ Medulloblastomas appear to metastasize by disseminating via the CSF to the leptomeningeal spaces of the brain and spine. ${ }^{81}$ The high rate of spinal metastases has made craniospinal radiation a mainstay of treatment for medulloblastoma, even if no lesions are visible on spinal images. In addition, the significant morbidity rates associated with craniospinal radiation in pediatric patients have motivated the pursuit of alternative, molecular genetics-guided therapeutic strategies.
Recent studies suggest that expression of distinct genes enables tumor cells to proliferate without surface attachment and to seed the leptomeningeal space. The Sleeping Beauty transposon system has been widely used to probe driver mutations in medulloblastoma. Developed in 1997, it helps insert gene fragments into the genome of animal medulloblastoma models without requiring viral vectors. ${ }^{71}$ Furthermore, development of a Patched model in mice has shown that overactive SHH signaling plays an important role in medulloblastoma initiation and dissemination within the spinal theca. ${ }^{46,71}$ Furthermore, insertional mutation of Patched in cerebellar granule precursor cells has helped identify this cell population as the origin of SHH-dependent medulloblastomas.98,124 The Sleeping Beauty system helped identify multiple gene candidates implicated in leptomeningeal dissemination, including Eras, Lhxl, Ccrk, Akt, Arnt, and Gdi2.46,71 These genes show high expression in aggressive cases of medulloblastoma and are important in cancer development.

In another study, inhibitor of differentiation 3 (ID3) expression was reported to be involved in greater leptomeningeal dissemination and worse prognosis in Group 4 tumors. ${ }^{80}$ Inhibitor of differentiation genes encode a family of transcription factors that suppress cell differentiation and regulate cell proliferation and migration in various cancers. Genomic analysis of medulloblastoma metastases to the spinal space is constrained by the limited indication for resection or biopsy, only rarely providing sufficient tissue on which to perform genetic analyses. Further development of genetic models will help identify and test therapeutic targets in medulloblastoma.

Although it is unknown how many different genes are required to initiate and maintain metastasis in individual patients, recent findings suggest that even a single gene mutation can promote metastatic transformation in medulloblastoma and seeding of the spinal meninges. Medulloblastoma models with mutations in Patched or $p 53$ show significant leptomeningeal dissemination and aberrant expression of several genes. In a study by Wu et al., ${ }^{122} 225$ mutated genes were observed in the metastatic Patched medulloblastoma model, and only 60 of these genes were associated with the primary tumor. Similarly, 72 mutated genes were observed in a p53-mutation background, and 8 of these mutations were associated with the original primary tumor. These results support the idea that an individual driver mutation can alter extensive oncological signaling networks and possibly induce therapeutic resistance. They also suggest distinct molecular differences between primary and metastatic diseases, supporting the idea that specific treatment paradigms may be necessary during treatment of disseminated medulloblastoma.

Targeting intracranial medulloblastoma has gained significant interest with the further characterization of the aforementioned 4 molecular subtypes. Several clinical trials have investigated the use of the inhibitors of the Smoothened receptor protein, LDE225, vismodegib, and sonidegib, alone or in combination with temozolomide in the clinical treatment of SHH-dependent medulloblastomas. ${ }^{54,65}$ Current approaches are also seeking to overcome resistance to Smoothened-dependent $\mathrm{SHH}$ pathway inhibition through the use of downstream effectors of the SHH pathway and via combinatorial treatments with the PI3K/ 
mTOR inhibitors arsenic or itraconazole. , $^{2,25,56}$ Inhibition of other medulloblastoma subtypes has been more limited. Targeting of Wnt pathway-dependent medulloblastomas is currently in progress with a Phase I evaluation of olaparib and veliparib. ${ }^{54,65}$ These compounds inhibit tankyrase-1, an activator of the Wnt signaling pathway that acts by poly-ADP ribosylation of AXIN1 and AXIN2, proteins that are involved in the $\beta$-catenin destruction complex. Studies of inhibitors of PI3K/mTOR, MAPKs, EGFR, and VEGF are also ongoing or are in early phases. Many of these agents are currently under investigation in recurring medulloblastoma; however, the extent to which these protein inhibitors target spinal medulloblastoma metastases has not been specifically reviewed.

\section{Disseminated Metastatic Cancers}

The extradural vertebral column is most frequently involved in bony metastasis, whereas purely intradural disease is uncommon and accounts for less than $6 \%$ of all spinal metastatic diseases. ${ }^{7,99,108}$ Up to $70 \%$ of cancer patients have spinal metastatic disease at the time of death, with the most common types arising from lung, prostate, and breast cancers. ${ }^{31}$ Intramedullary spinal cord metastasis (ISCM) is rare and is observed in fewer than $1 \%$ of all patients with systemic cancer. ${ }^{14}$ Lung and breast cancers are the most common primary tumors for ISCMs, ${ }^{107}$ although a diverse range of other cancers, including renal cell carcinoma ${ }^{52}$ and pituitary stalk germinomas, ${ }^{102}$ has reportedly metastasized to the intramedullary spinal cord. The most common site for metastatic disease is the thoracic spine $(70 \%)$, followed by the lumbar spine $(20 \%)$, cervical spine, and sacrum. ${ }^{99}$ Outcomes for patients with ISCMs are among the poorest of all for patients with intramedullary tumors, with a median length of survival of approximately 4 months from the time of diagnosis. ${ }^{107}$

Because of the rarity and heterogeneity of intradural metastatic disease and of ISCMs, precise molecular characterization of these tumors is less robust than that of bony metastatic disease. ${ }^{108,115}$ Non-small cell lung cancer frequently metastasizes to the cranial CNS, but its occurrence within the spinal cord remains rare, being encountered in approximately $2 \%$ of patients with this disease. ${ }^{77}$ Mutations in the anaplastic lymphoma kinase $(A L K)$ gene in non-small cell lung cancer appear to predispose patients to earlier and more aggressive CNS involvement, with 1 recent case series reporting a $4.2 \%$ rate of ISCM in ALKpositive individuals. ${ }^{29}$ The $A L K$ gene encodes a transmembrane tyrosine kinase that regulates multiple downstream mitogenic pathways and is involved in various tumors, including lymphoma, neuroblastoma, and non-small cell lung cancer. ${ }^{3}$ Nearly $15 \%$ of all instances of ISCM is attributable to breast cancer. ${ }^{50}$ Although much work has been done on the genetic alterations influencing metastasis to the brain, including mutations in $B R C A I^{1}$ and Her2/ $\mathrm{Neu},{ }^{70}$ little progress has been made on evaluating the risk factors for ISCM.

To help overcome the clinical research challenges due to the rarity of ISCM, animal models have been developed to identify candidate genes that increase the risk for ISCM development. The nuclear protein transcriptional regula- tor 1 (NUPR1), also known as candidate of metastasis-1, a chromatin-binding protein involved in histone regulation, generates intramedullary metastatic breast cancer in an experimental rat model $; 6$ however, the specific role of NUPR1 in regulating metastatic spinal disease remains controversial, and no further work has investigated its role specifically in ISCM. The genetic changes in intradural spinal metastases probably differ from those of vertebral body, intracranial, or systemic disease, and this difference may be important for treatment design and strategies. Additional comparisons of intradural and extradural metastatic diseases are warranted to better delineate genetic changes and clinical patterns.

Cancer metastasis is a complex multistep process that remains one of the most poorly understood facets of oncology. The process has been described as involving the initial dissemination of cancer cells from a primary tumor followed by a secondary colonization in a new microenvironment. ${ }^{12,61}$ Cancer metastasis to the spinal cord is rare and difficult to study clinically. Important to the understanding of metastasis has been the discovery of cancer stem cells, which are cells that have the potential to selfrenew, form additional cells of a cancer mass, and resist treatment. Targeting of these cancer stem cells has been 1 approach in molecular treatment of metastatic cancer. ${ }^{63}$ Metastatic cancer types may have some similarities, but they likely also harbor significant genetic differences that necessitate unique therapeutic strategies.

\section{Conclusions}

Intradural spinal tumors are often histologically similar to the intracranial counterparts with which they share a name, but otherwise are frequently genetically unique. These specific differences in genetic makeup suggest a potentially different pathogenesis that necessitates consideration of specific treatment modalities. Although resection remains a primary treatment option for most intradural spinal tumors, there is an increasing desire and ability to develop targeted chemotherapeutic interventions that can treat aggressive disease or offer options for salvage therapies. The application of the current knowledge gained from studies of cranial tumors will play an important role in the treatment of spinal cord tumors, despite the genetic differences between spinal tumors and their intracranial counterparts. In addition, specific treatments focused on a single molecular target may be useful across tumor types because of similar mechanisms that underlie their pathogenesis. Because of the rarity of intradural spinal tumors, collaborative, multicenter investigations will be required to fully realize the promise of targeted genetics-based therapies. ${ }^{127}$ Continued elucidation of the genetic features of these tumors will aid in the future design of treatment options and in clinical decision making.

\section{Acknowledgment}

We thank Kristin Kraus, MSc, for editorial assistance in preparing this paper.

\section{References}

1. Albiges L, André F, Balleyguier C, Gomez-Abuin G, Chom- 
pret A, Delaloge S: Spectrum of breast cancer metastasis in BRCA1 mutation carriers: highly increased incidence of brain metastases. Ann Oncol 16:1846-1847, 2005

2. Archer TC, Weeraratne SD, Pomeroy SL: Hedgehog-GLI pathway in medulloblastoma. J Clin Oncol 30:2154-2156, 2012

3. Ardini E, Magnaghi P, Orsini P, Galvani A, Menichincheri M: Anaplastic Lymphoma Kinase: role in specific tumours, and development of small molecule inhibitors for cancer therapy. Cancer Lett 299:81-94, 2010

4. Arslantas A, Artan S, Oner U, Durmaz R, Müslümanoglu H, Atasoy MA, et al: Detection of chromosomal imbalances in spinal meningiomas by comparative genomic hybridization. Neurol Med Chir (Tokyo) 43:12-19, 2003

5. Barresi V, Alafaci C, Caffo M, Barresi G, Tuccari G: Clinicopathological characteristics, hormone receptor status and matrix metallo-proteinase-9 (MMP-9) immunohistochemical expression in spinal meningiomas. Pathol Res Pract 208:350-355, 2012

6. Barresi V, Vitarelli E, Tuccari G, Barresi G: MMP-9 expression in meningiomas: a prognostic marker for recurrence risk? J Neurooncol 102:189-196, 2011

7. Bartels RH, van der Linden YM, van der Graaf WT: Spinal extradural metastasis: review of current treatment options. CA Cancer J Clin 58:245-259, 2008

8. Bettegowda C, Agrawal N, Jiao Y, Wang Y, Wood LD, Rodriguez FJ, et al: Exomic sequencing of four rare central nervous system tumor types. Oncotarget 4:572-583, 2013

9. Buonamici S, Williams J, Morrissey M, Wang A, Guo R, Vattay A, et al: Interfering with resistance to smoothened antagonists by inhibition of the PI3K pathway in medulloblastoma. Sci Transl Med 2:51 ra70, 2010

10. Cancer Genome Atlas Research Network: Comprehensive genomic characterization of squamous cell lung cancers. Nature 489:519-525, 2012

11. Carter M, Nicholson J, Ross F, Crolla J, Allibone R, Balaji V, et al: Genetic abnormalities detected in ependymomas by comparative genomic hybridisation. Br J Cancer 86:929939, 2002

12. Chaffer CL, Weinberg RA: A perspective on cancer cell metastasis. Science 331:1559-1564, 2011

13. Cho YJ, Tsherniak A, Tamayo P, Santagata S, Ligon A, Greulich $\mathrm{H}$, et al: Integrative genomic analysis of medulloblastoma identifies a molecular subgroup that drives poor clinical outcome. J Clin Oncol 29:1424-1430, 2011

14. Costigan DA, Winkelman MD: Intramedullary spinal cord metastasis. A clinicopathological study of 13 cases. J Neurosurg 62:227-233, 1985

15. de Haas S, Delmar P, Bansal AT, Moisse M, Miles DW, Leighl N, et al: Genetic variability of VEGF pathway genes in six randomized phase III trials assessing the addition of bevacizumab to standard therapy. Angiogenesis 17:909-920, 2014

16. De La Garza-Ramos R, Flores-Rodríguez JV, MartínezGutiérrez JC, Ruiz-Valls A, Caro-Osorio E: Current standing and frontiers of gene therapy for meningiomas. Neurosurg Focus 35(6):E4, 2013

17. Dey M, Auffinger B, Lesniak MS, Ahmed AU: Antiglioma oncolytic virotherapy: unattainable goal or a success story in the making? Future Virol 8:675-693, 2013

18. Dolecek TA, Propp JM, Stroup NE, Kruchko C: CBTRUS statistical report: primary brain and central nervous system tumors diagnosed in the United States in 2005-2009. Neuro Oncol 14 (Suppl 5):v1-v49, 2012

19. Dow G, Biggs N, Evans G, Gillespie J, Ramsden R, King A: Spinal tumors in neurofibromatosis type 2. Is emerging knowledge of genotype predictive of natural history? J Neurosurg Spine 2:574-579, 2005

20. Ebert C, von Haken M, Meyer-Puttlitz B, Wiestler OD, Reifenberger G, Pietsch T, et al: Molecular genetic analysis of ependymal tumors. NF2 mutations and chromosome 22q loss occur preferentially in intramedullary spinal ependymomas. Am J Pathol 155:627-632, 1999

21. Ellison DW, Kocak M, Dalton J, Megahed H, Lusher ME, Ryan SL, et al: Definition of disease-risk stratification groups in childhood medulloblastoma using combined clinical, pathologic, and molecular variables. J Clin Oncol 29:14001407, 2011

22. England B, Huang T, Karsy M: Current understanding of the role and targeting of tumor suppressor p53 in glioblastoma multiforme. Tumour Biol 34:2063-2074, 2013

23. Evans DG, Howard E, Giblin C, Clancy T, Spencer H, Huson SM, et al: Birth incidence and prevalence of tumor-prone syndromes: estimates from a UK family genetic register service. Am J Med Genet A 152A:327-332, 2010

24. Fakhrai N, Neophytou P, Dieckmann K, Nemeth A, Prayer D, Hainfellner J, et al: Recurrent spinal ependymoma showing partial remission under Imatimib. Acta Neurochir (Wien) 146:1255-1258, 2004

25. Faria CC, Golbourn BJ, Dubuc AM, Remke M, Diaz RJ, Agnihotri S, et al: Foretinib is effective therapy for metastatic sonic hedgehog medulloblastoma. Cancer Res 75:134-146, 2015

26. Ferroni L, Della Puppa A, D’Avella D, Isola M, Scienza R, Gardin C, et al: Tissue engineering strategies as tools for personalized meningioma treatment. Artif Organs 39:E114E126, 2015

27. Fouladi M, Stewart CF, Olson J, Wagner LM, Onar-Thomas A, Kocak M, et al: Phase I trial of MK-0752 in children with refractory CNS malignancies: a pediatric brain tumor consortium study. J Clin Oncol 29:3529-3534, 2011

28. Frantzen C, Links TP, Giles RH: Von Hippel-Lindau disease, in Pagon RA, Adam MP, Ardinger HH, et al (eds): GeneReviews $^{\circledR}$. Seattle: University of Washington, Seattle, 2000

29. Gainor JF, Ou SH, Logan J, Borges LF, Shaw AT: The central nervous system as a sanctuary site in ALK-positive nonsmall-cell lung cancer. J Thorac Oncol 8:1570-1573, 2013

30. Gajjar AJ, Robinson GW: Medulloblastoma-translating discoveries from the bench to the bedside. Nat Rev Clin Oncol 11:714-722, 2014

31. Galasko CS: Diagnosis of skeletal metastases and assessment of response to treatment. Clin Orthop Relat Res (312):6475,1995

32. Gillespie DL, Whang K, Ragel BT, Flynn JR, Kelly DA, Jensen RL: Silencing of hypoxia inducible factor-1alpha by RNA interference attenuates human glioma cell growth in vivo. Clin Cancer Res 13:2441-2448, 2007

33. Gläsker S: Central nervous system manifestations in VHL: genetics, pathology and clinical phenotypic features. Fam Cancer 4:37-42, 2005

34. Govindan A, Chakraborti S, Mahadevan A, Chickabasavaiah YT, Santosh V, Shankar SK: Histopathologic and immunohistochemical profile of spinal glioblastoma: a study of six cases. Brain Tumor Pathol 28:297-303, 2011

35. Gulati N, Karsy M, Albert L, Murali R, Jhanwar-Uniyal $\mathrm{M}$ : Involvement of mTORC1 and mTORC2 in regulation of glioblastoma multiforme growth and motility. Int J Oncol 35:731-740, 2009

36. Gupta R, Nalla AK, Gogineni VR, Chetty C, Bhoopathi P, Klopfenstein JD, et al: uPAR/cathepsin B overexpression reverse angiogenesis by rescuing FAK phosphorylation in uPAR/cathepsin B down regulated meningioma. PLoS ONE 6:e17123, 2011

37. Haddad NM, Cavallerano JD, Silva PS: Von Hippel-Lindau disease: a genetic and clinical review. Semin Ophthalmol 28:377-386, 2013

38. Hawasli AH, Rubin JB, Tran DD, Adkins DR, Waheed S, Hullar TE, et al: Antiangiogenic agents for nonmalignant brain tumors. J Neurol Surg B Skull Base 74:136-141, 2013

39. Hawkins C, Walker E, Mohamed N, Zhang C, Jacob K, Shirinian M, et al: BRAF-KIAA1549 fusion predicts better 
clinical outcome in pediatric low-grade astrocytoma. Clin Cancer Res 17:4790-4798, 2011

40. Horbinski C, Hamilton RL, Nikiforov Y, Pollack IF: Association of molecular alterations, including BRAF, with biology and outcome in pilocytic astrocytomas. Acta Neuropathol 119:641-649, 2010

41. Hrisomalos FN, Maturi RK, Pata V: Long-term use of intravitreal bevacizumab (avastin) for the treatment of von Hippel-Lindau associated retinal hemangioblastomas. Open Ophthalmol J 4:66-69, 2010

42. Huang T, Karsy M, Zhuge J, Zhong M, Liu D: B-Raf and the inhibitors: from bench to bedside. J Hematol Oncol 6:30, 2013

43. Hulsebos TJ, Plomp AS, Wolterman RA, Robanus-Maandag EC, Baas F, Wesseling P: Germline mutation of INI1/ SMARCB1 in familial schwannomatosis. Am J Hum Genet 80:805-810, 2007

44. Ikeda K, Saeki Y, Gonzalez-Agosti C, Ramesh V, Chiocca EA: Inhibition of NF2-negative and NF2-positive primary human meningioma cell proliferation by overexpression of merlin due to vector-mediated gene transfer. J Neurosurg 91:85-92, 1999

45. Jakacki RI, Dombi E, Potter DM, Goldman S, Allen JC, Pollack IF, et al: Phase I trial of pegylated interferon-alpha-2b in young patients with plexiform neurofibromas. Neurology 76:265-272, 2011

46. Jenkins NC, Kalra RR, Dubuc A, Sivakumar W, Pedone CA, Wu X, et al: Genetic drivers of metastatic dissemination in sonic hedgehog medulloblastoma. Acta Neuropathol Commun 2:85, 2014

47. Jessen WJ, Miller SJ, Jousma E, Wu J, Rizvi TA, Brundage ME, et al: MEK inhibition exhibits efficacy in human and mouse neurofibromatosis tumors. J Clin Invest 123:340347, 2013

48. Jett K, Friedman JM: Clinical and genetic aspects of neurofibromatosis 1. Genet Med 12:1-11, 2010

49. Johnson RA, Wright KD, Poppleton H, Mohankumar KM, Finkelstein D, Pounds SB, et al: Cross-species genomics matches driver mutations and cell compartments to model ependymoma. Nature 466:632-636, 2010

50. Kaal EC, Vecht CJ: CNS complications of breast cancer: current and emerging treatment options. CNS Drugs 21:559579,2007

51. Karsy M, Neil JA, Guan J, Mark MA, Colman H, Jensen RL: A practical review of prognostic correlations of molecular biomarkers in glioblastoma. Neurosurg Focus 38(3):E4, 2015

52. Kaya RA, Dalkiliç T, Ozer F, Aydin Y: Intramedullary spinal cord metastasis: a rare and devastating complication of cancer-two case reports. Neurol Med Chir (Tokyo) 43:612-615, 2003

53. Khasraw M, Ameratunga MS, Grant R, Wheeler H, Pavlakis $\mathrm{N}$ : Antiangiogenic therapy for high-grade glioma. Cochrane Database Syst Rev 9:CD008218, 2014

54. Kieran MW: Targeted treatment for sonic hedgehog-dependent medulloblastoma. Neuro Oncol 16:1037-1047, 2014

55. Kim A, Dombi E, Tepas K, Fox E, Martin S, Wolters P, et al: Phase I trial and pharmacokinetic study of sorafenib in children with neurofibromatosis type I and plexiform neurofibromas. Pediatr Blood Cancer 60:396-401, 2013

56. Kim J, Aftab BT, Tang JY, Kim D, Lee AH, Rezaee M, et al: Itraconazole and arsenic trioxide inhibit Hedgehog pathway activation and tumor growth associated with acquired resistance to smoothened antagonists. Cancer Cell 23:23-34, 2013

57. Kim YH, Ohta T, Oh JE, Le Calvez-Kelm F, McKay J, Voegele C, et al: TP53, MSH4, and LATS1 germline mutations in a family with clustering of nervous system tumors. Am J Pathol 184:2374-2381, 2014
58. Kimura H, Zhang L, Zhao M, Hayashi K, Tsuchiya H, Tomita K, et al: Targeted therapy of spinal cord glioma with a genetically modified Salmonella typhimurium. Cell Prolif 43:41-48, 2010

59. Kool M, Koster J, Bunt J, Hasselt NE, Lakeman A, van Sluis $\mathrm{P}$, et al: Integrated genomics identifies five medulloblastoma subtypes with distinct genetic profiles, pathway signatures and clinicopathological features. PLoS ONE 3:e3088, 2008

60. Korshunov A, Neben K, Wrobel G, Tews B, Benner A, Hahn $\mathrm{M}$, et al: Gene expression patterns in ependymomas correlate with tumor location, grade, and patient age. Am J Pathol 163:1721-1727, 2003

61. Kraljevic Pavelic S, Sedic M, Bosnjak H, Spaventi S, Pavelic K: Metastasis: new perspectives on an old problem. Mol Cancer 10:22, 2011

62. Kramm CM, Korholz D, Rainov NG, Niehues T, Fischer U, Steffens S, et al: Systemic activation of the immune system during ganciclovir treatment following intratumoral herpes simplex virus type 1 thymidine kinase gene transfer in an adolescent ependymoma patient. Neuropediatrics 33:6-9, 2002

63. Li S, Li Q: Cancer stem cells and tumor metastasis. Int J Oncol 44:1806-1812, 2014

64. Lou E, Sumrall AL, Turner S, Peters KB, Desjardins A, Vredenburgh JJ, et al: Bevacizumab therapy for adults with recurrent/progressive meningioma: a retrospective series. J Neurooncol 109:63-70, 2012

65. MacDonald TJ, Aguilera D, Castellino RC: The rationale for targeted therapies in medulloblastoma. Neuro Oncol 16:9-20, 2014

66. Maria BL, Gupta N, Gilg AG, Abdel-Wahab M, Leonard AP, Slomiany M, et al: Targeting hyaluronan interactions in spinal cord astrocytomas and diffuse pontine gliomas. J Child Neurol 23:1214-1220, 2008

67. McCormick PC: Surgical management of dumbbell tumors of the cervical spine. Neurosurgery 38:294-300, 1996

68. Mendrzyk F, Korshunov A, Benner A, Toedt G, Pfister $\mathrm{S}$, Radlwimmer B, et al: Identification of gains on 1q and epidermal growth factor receptor overexpression as independent prognostic markers in intracranial ependymoma. Clin Cancer Res 12:2070-2079, 2006

69. Milde T, Kleber S, Korshunov A, Witt H, Hielscher T, Koch P, et al: A novel human high-risk ependymoma stem cell model reveals the differentiation-inducing potential of the histone deacetylase inhibitor Vorinostat. Acta Neuropathol 122:637-650, 2011

70. Miller KD, Weathers T, Haney LG, Timmerman R, Dickler $\mathrm{M}$, Shen J, et al: Occult central nervous system involvement in patients with metastatic breast cancer: prevalence, predictive factors and impact on overall survival. Ann Oncol 14:1072-1077, 2003

71. Mumert M, Dubuc A, Wu X, Northcott PA, Chin SS, Pedone CA, et al: Functional genomics identifies drivers of medulloblastoma dissemination. Cancer Res 72:4944-4953, 2012

72. Nadkarni TD, Rekate HL: Pediatric intramedullary spinal cord tumors. Critical review of the literature. Childs Nerv Syst 15:17-28, 1999

73. Nayak L, Iwamoto FM, Rudnick JD, Norden AD, Lee EQ, Drappatz J, et al: Atypical and anaplastic meningiomas treated with bevacizumab. J Neurooncol 109:187-193, 2012

74. Nelson JB, Hedican SP, George DJ, Reddi AH, Piantadosi S, Eisenberger MA, et al: Identification of endothelin-1 in the pathophysiology of metastatic adenocarcinoma of the prostate. Nat Med 1:944-949, 1995

75. Northcott PA, Korshunov A, Witt H, Hielscher T, Eberhart CG, Mack S, et al: Medulloblastoma comprises four distinct molecular variants. J Clin Oncol 29:1408-1414, 2011

76. Nunes FP, Merker VL, Jennings D, Caruso PA, di Tomaso E, Muzikansky A, et al: Bevacizumab treatment for meningiomas in NF2: a retrospective analysis of 15 patients. PLoS ONE 8:e59941, 2013 
77. Okamoto H, Shinkai T, Matsuno Y, Saijo N: Intradural parenchymal involvement in the spinal subarachnoid space associated with primary lung cancer. Cancer 72:25832588, 1993

78. Ostrom QT, Gittleman H, Liao P, Rouse C, Chen Y, Dowling J, et al: CBTRUS statistical report: primary brain and central nervous system tumors diagnosed in the United States in 2007-2011. Neuro Oncol 16 (Suppl 4):iv1-iv63, 2014

79. Pham MH, Zada G, Mosich GM, Chen TC, Giannotta SL, Wang K, et al: Molecular genetics of meningiomas: a systematic review of the current literature and potential basis for future treatment paradigms. Neurosurg Focus 30(5):E7, 2011

80. Phi JH, Choi SA, Lim SH, Lee J, Wang KC, Park SH, et al: ID3 contributes to cerebrospinal fluid seeding and poor prognosis in medulloblastoma. BMC Cancer 13:291, 2013

81. Pollack IF: Multidisciplinary management of childhood brain tumors: a review of outcomes, recent advances, and challenges. J Neurosurg Pediatr 8:135-148, 2011

82. Prowse AH, Webster AR, Richards FM, Richard S, Olschwang S, Resche F, et al: Somatic inactivation of the VHL gene in Von Hippel-Lindau disease tumors. Am J Hum Genet 60:765-771, 1997

83. Puchner MJ, Hans VH, Harati A, Lohmann F, Glas M, Herrlinger U: Bevacizumab-induced regression of anaplastic meningioma. Ann Oncol 21:2445-2446, 2010

84. Rao G, Pedone CA, Coffin CM, Holland EC, Fults DW: c-Myc enhances sonic hedgehog-induced medulloblastoma formation from nestin-expressing neural progenitors in mice. Neoplasia 5:198-204, 2003

85. Rao G, Pedone CA, Del Valle L, Reiss K, Holland EC, Fults DW: Sonic hedgehog and insulin-like growth factor signaling synergize to induce medulloblastoma formation from nestin-expressing neural progenitors in mice. Oncogene 23:6156-6162, 2004

86. Ree AH, Tvermyr M, Engebraaten O, Rooman M, Røsok O, Hovig E, et al: Expression of a novel factor in human breast cancer cells with metastatic potential. Cancer Res 59:4675-4680, 1999

87. Ren X, Wang J, Hu M, Jiang H, Yang J, Jiang Z: Clinical, radiological, and pathological features of 26 intracranial and intraspinal malignant peripheral nerve sheath tumors. J Neurosurg 119:695-708, 2013

88. Robert C, Long GV, Brady B, Dutriaux C, Maio M, Mortier $\mathrm{L}$, et al: Nivolumab in previously untreated melanoma without BRAF mutation. N Engl J Med 372:320-330, 2015

89. Robertson KA, Nalepa G, Yang FC, Bowers DC, Ho CY, Hutchins GD, et al: Imatinib mesylate for plexiform neurofibromas in patients with neurofibromatosis type 1: a phase 2 trial. Lancet Oncol 13:1218-1224, 2012

90. Robinson GW, Orr BA, Gajjar A: Complete clinical regression of a BRAF V600E-mutant pediatric glioblastoma multiforme after BRAF inhibitor therapy. BMC Cancer 14:258, 2014

91. Rogers HA, Mayne C, Chapman RJ, Kilday JP, Coyle B, Grundy RG: PI3K pathway activation provides a novel therapeutic target for pediatric ependymoma and is an independent marker of progression-free survival. Clin Cancer Res 19:6450-6460, 2013

92. Roodman GD: Mechanisms of bone metastasis. N Engl J Med 350:1655-1664, 2004

93. Sami A, Karsy M: Targeting the PI3K/AKT/mTOR signaling pathway in glioblastoma: novel therapeutic agents and advances in understanding. Tumour Biol 34:1991-2002, 2013

94. Sandalcioglu IE, Hunold A, Müller O, Bassiouni H, Stolke D, Asgari S: Spinal meningiomas: critical review of 131 surgically treated patients. Eur Spine J 17:1035-1041, 2008

95. Sayagués JM, Tabernero MD, Maíllo A, Trelles O, Espinosa
$\mathrm{AB}$, Sarasquete ME, et al: Microarray-based analysis of spinal versus intracranial meningiomas: different clinical, biological, and genetic characteristics associated with distinct patterns of gene expression. J Neuropathol Exp Neurol 65:445-454, 2006

96. Schaller B: Spinal meningioma: relationship between histological subtypes and surgical outcome? J Neurooncol 75:157-161, 2005

97. Schroeder RD, Angelo LS, Kurzrock R: NF2/merlin in hereditary neurofibromatosis 2 versus cancer: biologic mechanisms and clinical associations. Oncotarget 5:67-77, 2014

98. Schüller U, Heine VM, Mao J, Kho AT, Dillon AK, Han YG, et al: Acquisition of granule neuron precursor identity is a critical determinant of progenitor cell competence to form Shh-induced medulloblastoma. Cancer Cell 14:123134, 2008

99. Sciubba DM, Petteys RJ, Dekutoski MB, Fisher CG, Fehlings MG, Ondra SL, et al: Diagnosis and management of metastatic spine disease. A review. J Neurosurg Spine 13:94-108, 2010

100. Servidei T, Meco D, Trivieri N, Patriarca V, Vellone VG, Zannoni GF, et al: Effects of epidermal growth factor receptor blockade on ependymoma stem cells in vitro and in orthotopic mouse models. Int J Cancer 131:E791-E803, 2012

101. Setzer M, Vatter H, Marquardt G, Seifert V, Vrionis FD: Management of spinal meningiomas: surgical results and a review of the literature. Neurosurg Focus 23(4):E14, 2007

102. Shah KC, Chacko G, John S, Chacko AG: Spinal intramedullary metastasis from intracranial germinoma. Neurol India 53:374-375, 2005

103. Shu J, Lee JH, Harwalkar JA, Oh-Siskovic S, Stacey DW, Golubić M: Adenovirus-mediated gene transfer of dominant negative Ha-Ras inhibits proliferation of primary meningioma cells. Neurosurgery 44:579-588, 1999

104. Singh PK, Gutmann DH, Fuller CE, Newsham IF, Perry A: Differential involvement of protein 4.1 family members DAL-1 and NF2 in intracranial and intraspinal ependymomas. Mod Pathol 15:526-531, 2002

105. Smith MJ, O'Sullivan J, Bhaskar SS, Hadfield KD, Poke $\mathrm{G}$, Caird J, et al: Loss-of-function mutations in SMARCE1 cause an inherited disorder of multiple spinal meningiomas. Nat Genet 45:295-298, 2013

106. Smith MJ, Wallace AJ, Bennett C, Hasselblatt M, ElertDobkowska E, Evans LT, et al: Germline SMARCE1 mutations predispose to both spinal and cranial clear cell meningiomas. J Pathol 234:436-440, 2014

107. Sung WS, Sung MJ, Chan JH, Manion B, Song J, Dubey A, et al: Intramedullary spinal cord metastases: a 20 -year institutional experience with a comprehensive literature review. World Neurosurg 79:576-584, 2013

108. Sutcliffe P, Connock M, Shyangdan D, Court R, Kandala NB, Clarke A: A systematic review of evidence on malignant spinal metastases: natural history and technologies for identifying patients at high risk of vertebral fracture and spinal cord compression. Health Technol Assess 17:1-274, 2013

109. Takai K, Taniguchi M, Takahashi H, Usui M, Saito N: Comparative analysis of spinal hemangioblastomas in sporadic disease and Von Hippel-Lindau syndrome. Neurol Med Chir (Tokyo) 50:560-567, 2010

110. Taylor MD, Poppleton H, Fuller C, Su X, Liu Y, Jensen P, et al: Radial glia cells are candidate stem cells of ependymoma. Cancer Cell 8:323-335, 2005

111. Thompson MC, Fuller C, Hogg TL, Dalton J, Finkelstein D, Lau CC, et al: Genomics identifies medulloblastoma subgroups that are enriched for specific genetic alterations. J Clin Oncol 24:1924-1931, 2006

112. Traul DE, Shaffrey ME, Schiff D: Part I: spinal-cord neoplasms-intradural neoplasms. Lancet Oncol 8:35-45, 2007 
113. Tummalapalli P, Spomar D, Gondi CS, Olivero WC, Gujrati M, Dinh DH, et al: RNAi-mediated abrogation of cathepsin $\mathrm{B}$ and MMP-9 gene expression in a malignant meningioma cell line leads to decreased tumor growth, invasion and angiogenesis. Int J Oncol 31: 1039-1050, 2007

114. Vera-Bolanos E, Aldape K, Yuan Y, Wu J, Wani K, Necesito-Reyes MJ, et al: Clinical course and progressionfree survival of adult intracranial and spinal ependymoma patients. Neuro Oncol 17:440-447, 2014

115. Weilbaecher KN, Guise TA, McCauley LK: Cancer to bone: a fatal attraction. Nat Rev Cancer 11:411-425, 2011

116. Weiss B, Widemann BC, Wolters P, Dombi E, Vinks AA, Cantor A, et al: Sirolimus for non-progressive NF1associated plexiform neurofibromas: an NF clinical trials consortium phase II study. Pediatr Blood Cancer 61:982986, 2014

117. Widemann BC, Dombi E, Gillespie A, Wolters PL, Belasco $\mathrm{J}$, Goldman S, et al: Phase 2 randomized, flexible crossover, double-blinded, placebo-controlled trial of the farnesyltransferase inhibitor tipifarnib in children and young adults with neurofibromatosis type 1 and progressive plexiform neurofibromas. Neuro Oncol 16:707-718, 2014

118. Widemann BC, Salzer WL, Arceci RJ, Blaney SM, Fox E, End D, et al: Phase I trial and pharmacokinetic study of the farnesyltransferase inhibitor tipifarnib in children with refractory solid tumors or neurofibromatosis type I and plexiform neurofibromas. J Clin Oncol 24:507-516, 2006

119. Witt H, Korshunov A, Pfister SM, Milde T: Molecular approaches to ependymoma: the next step(s). Curr Opin Neurol 25:745-750, 2012

120. Wollmann G, Ozduman K, van den Pol AN: Oncolytic virus therapy for glioblastoma multiforme: concepts and candidates. Cancer J 18:69-81, 2012

121. Wu G, Broniscer A, McEachron TA, Lu C, Paugh BS, Becksfort J, et al: Somatic histone $\mathrm{H} 3$ alterations in pediatric diffuse intrinsic pontine gliomas and non-brainstem glioblastomas. Nat Genet 44:251-253, 2012
122. Wu X, Northcott PA, Dubuc A, Dupuy AJ, Shih DJ, Witt $\mathrm{H}$, et al: Clonal selection drives genetic divergence of metastatic medulloblastoma. Nature 482:529-533, 2012

123. Yamasaki T, Kamba T, Kanno T, Inoue T, Shibasaki N, Arakaki R, et al: Tumor microvasculature with endothelial fenestrations in VHL null clear cell renal cell carcinomas as a potent target of anti-angiogenic therapy. Cancer Sci 103:2027-2037, 2012

124. Yang ZJ, Ellis T, Markant SL, Read TA, Kessler JD, Bourboulas M, et al: Medulloblastoma can be initiated by deletion of Patched in lineage-restricted progenitors or stem cells. Cancer Cell 14:135-145, 2008

125. Yap YS, McPherson JR, Ong CK, Rozen SG, Teh BT, Lee AS, et al: The NF1 gene revisited - from bench to bedside. Oncotarget 5:5873-5892, 2014

126. Yeung JT, Hamilton RL, Okada H, Jakacki RI, Pollack IF: Increased expression of tumor-associated antigens in pediatric and adult ependymomas: implication for vaccine therapy. J Neurooncol 111:103-111, 2013

127. Zadnik PL, Gokaslan ZL, Burger PC, Bettegowda C: Spinal cord tumours: advances in genetics and their implications for treatment. Nat Rev Neurol 9:257-266, 2013

\section{Author Contributions}

Conception and design: Mahan, Karsy, Guan, Sivakumar, Neil. Drafting the article: all authors. Critically revising the article: all authors. Reviewed submitted version of manuscript: all authors. Approved the final version of the manuscript on behalf of all authors: Mahan.

\section{Correspondence}

Mark A. Mahan, Department of Neurosurgery, Clinical Neurosciences Center, The University of Utah, 175 N. Medical Dr. E, Salt Lake City, UT 84132. email: mark.mahan@hsc.utah. edu. 